\title{
Sexual Difference
}

\section{Abstract}

This chapter explains the main conceptions of sexual difference that have influenced feminist theory, tracing their roots in the psychoanalysis of Freud and Lacan, then introducing the radical rethinking of sexual difference put forward by Luce Irigaray. For Irigaray, in the Western symbolic order there has only ever been sexual hierarchy, not genuine sexual difference. Her political program of changing the symbolic order to create a positive feminine subject-position - one that is not merely the underside or negative opposite of the masculine position - has been developed practically by some Italian feminists. Conceptions of sexual difference have also helped feminist theorists to rethink embodiment beyond the sex/gender distinction. The chapter concludes by considering how conceptions of sexual difference have made possible various current directions in feminist theory including the new 'material feminisms'.

\section{Keywords:}

body, embodiment, Freud, Irigaray, Italian feminism, Lacan, psychoanalysis, sex/gender distinction, sexual difference, symbolic order 


\section{Sexual Difference}

Introduction

A family of related concepts of sexual difference has become part of feminist theory, stemming from two main sources: the psychoanalytic theories of Freud and Lacan and the work of the Belgian-born philosopher Luce Irigaray, herself also a practicing psychoanalyst. Ever since the 1970s their ideas of sexual difference have been embraced by some English-speaking feminist theorists, for a cluster of overlapping reasons. These reasons will provide the framework structuring this chapter, each being considered in turn.

First (Section 1), the concept of sexual difference has provided a framework within which to recognize that the psyche is not reducible to society, and that masculinity and femininity have deep and enduring roots in our psyches, being acquired together with the fundamental fantasies and mental agencies (of desire, repression, conscience, etc.) that compose our minds. Second (Section 2), the concept of sexual difference has enabled feminists to theorize the nature of the symbolic order. Not straightforwardly the same as society, a symbolic order is a set of fundamental, systematically organized meanings which structure our psyches across a diverse range of cultures and societies that all participate in the same order. Any symbolic order is embodied in language - which, not simply a neutral tool of communication, constitutes an overarching horizon of meaning and framework for experience - and in other 'discursive and signifying systems': visual art, religion, music, architecture - the whole 'dimension of representations' (Grosz 1990: 22). In the West, the order of meanings embodied across all these fields has revolved around 
the hierarchical opposition man/woman, or so Irigaray and others have claimed. Third (Section 3), feminist analysis of the Western symbolic has generated a politics of sexual difference. Its aim is to change the symbolic order, and accompanying social practices, to create a positive feminine subject-position. Traditionally the West has ruled this out by construing woman merely as an inferior version of man - as when Freud judges the clitoris a defective, shrunken penis. Fourth (Section 4), the concept of sexual difference has helped feminists to rethink embodiment beyond the sex/gender distinction. Finally, there is a range of contemporary engagements with ideas of sexual difference (Section 5), including the new 'material feminisms' which both build on and critique sexual difference feminism's approach to embodiment.

\section{Psychoanalytic Roots of the Concept of Sexual Difference}

Psychoanalysis is the key intellectual tradition through which the concept of sexual difference has entered feminist theory. So we must re-examine Freud's account of masculinity and femininity and then Lacan's revision of this account, which has been crucial to the feminist reception of psychoanalysis.

Freud came to pay serious attention to femininity only late in his intellectual career. Until then, he approached femininity in terms of the same theory of the Oedipus complex that he had originally developed with reference to little boys. Bracketing the many problems surrounding this theory, let us review its essentials.

For Freud, every young boy, from his third to fifth years, has sexual wishes for his mother and hates his rival, the father, whom the boy wishes to kill. These sexual wishes are not for intercourse specifically but for various, vaguely imagined, kinds of bodily intimacy with the mother. To punish the boy for these wishes he is threatened 
with castration, either by the father or by others invoking his name. This threat eventually prompts the boy to dissolve his Oedipus complex. He represses his sexual wishes for his mother, henceforward letting them become conscious only in the form of desexualized affection. He also represses his rivalrous hatred for his father, in return for the assurance that he will grow up to be a father in his own right and to 'possess' his own wife - a stand-in for his beloved mother.

Initially Freud assumed that the little girl has an inversely symmetrical Oedipus complex in which she has sexual wishes for her father and hatefully competes with her mother. Freud gradually abandoned that assumption. He set out his amended position in the 1925 essay 'Some Psychical Consequences of the Anatomical Distinction between the Sexes', 1931’s 'Female Sexuality’ and 1933’s ‘Femininity’ (see respectively Freud 1977a, 1977b, 1973).

Both girls and boys first love their mothers, Freud concedes now. This is presumably due to the social convention for women and mothers to be the primary child-carers, although Freud does not spell this out. Supposedly the girl loves her mother in the same 'phallic' way as the boy, wanting to perform sexual acts with her mother using her clitoris as if it were a penis. Whereas the boy relinquishes his love for his mother owing to the threat of castration, the five-year-old girl comes to reject her mother on 'discovering' that she and her mother are already castrated, lacking the penis. In hindsight the girl blames her mother for all her other disappointments weaning, toilet-training, displacement by younger siblings, etc.

Now hating her mother, the girl becomes contemptuous of other women too, including herself. Assuming that she follows the path of 'normal femininity', she takes her father as her new love, wanting through him to access a penis. From now on, she has an Oedipus complex: she loves her father and hates her mother. The girl never 
properly abandons this complex, for she cannot be propelled out of it by threats of castration. Rather her castration complex pushes her into the Oedipus complex and leaves her there - more or less. At best she realizes that she can never possess a penis and instead comes to wish to have a baby with first her father and then a fathersubstitute - ideally a baby boy, through whom she can access a penis.

Implied by Freud's work is a conceptual distinction between sexual difference and anatomical sex difference: sexual difference is not the same as sex difference but its psychical consequence. ${ }^{1}$ Sexual difference is between the different subjectpositions or sexed identities assumed by girls and boys and retained by women and men. These positions are composed of the different relationships that men and women adopt to others (e.g. loving versus hating their mothers), their different selfperceptions (as future fathers or castrated), and different sets of desires and wishes (for a mother-substitute versus a penis). This psychical difference is sexual for Freud because it arises from the different courses of erotic development that girls and boys undergo, the different ways that their desires become structured and the different ways that their psyches become organized around these desires.

In specifying that children acquire sexed identities only through these tortuous courses of development, Freud takes it that children begin life without any stable sexed identities - they are originally polymorphous or bisexual, as he variously puts it. This too distinguishes sexual from sex difference: the latter is given at birth; the former acquired through complex, difficult processes. By implication sexed identity is never entirely stable or complete: because it always emerges from an individual's pre-

\footnotetext{
${ }^{1}$ Freud does not make the distinction terminologically, except insofar as he speaks of 'anatomical sex difference' (in German: anatomische Geschlechtsunterschied) as distinct from Geschlechtsunterschied as such. Moreover, he speaks not of subjectpositions - a later, yet still helpful term - but of 'psychical maleness' and 'psychical femaleness'.
} 
sexed past, everyone harbors psychical forces and desires that destabilize their acquired sexed identity. Even so, sexed identities generally endure - but despite the instabilities that continually beset them. Whereas sex is (we assume for now) fixed, sexed identities (and sexual difference) are precarious and volatile.

Since sexual difference is not anatomical but psychical (and eroticized, acquired, unstable), does sexual difference stand to sex as gender stands to sex? Is sexual difference just another word for gender? Let us see why not.

When the sex/gender distinction, first made by psychologists, was introduced into feminist thought, it was widely understood as follows. Sex is the biological difference between males and females; gender consists of societies' different expectations and roles for males and females (e.g. to be aggressive versus peaceful) and the differences between men's and women's personalities as they become shaped by these expectations. Biological males and females become socially masculine and feminine as they become gendered. Many feminists embraced this sex/gender distinction because it meant that men's and women's personalities and social roles are shaped by social norms rather than being direct effects of biology. And whereas biology is fixed, roles and norms vary across societies (Oakley 1972: 128); therefore we can change these norms so that they stop steering men and women in opposed and unequal directions.

In contrast, Freud's perspective is that the psyche has its own dynamics, possibilities and pathways, whatever gender norms prevail socially. Indeed, we only become responsive to either masculine or feminine roles on the basis of first acquiring the rudiments of a psychical identity as masculine or feminine. We do that by way of the castration and Oedipus complexes - stages that each individual must pass through psychically, regardless of their varied social situations. A core psychoanalytic insight, 
then, is that the psyche and its development are not reducible to, but have a level of independence of, society. As such, the psychical difference between the sexes is not reducible to social gender difference. Rather, in every society this psychical difference must exist; each society must accommodate it in some way. ${ }^{2}$

Further, for Freud, the psyche is not reducible to the mind as opposed to the body - whereas, under the sex/gender distinction as it was initially understood, gender obtains in the mind, sex in the body. Freud instead treats the psyche and each of its component agencies (ego, superego, etc.) as an organization of ideas and physical energies at once. As ideas become stabilized into fixed patterns, so our corresponding physical energies become bound into desires, drives, patterns of activity, gestures, habits, etc. For example, when someone suffering from hysteria represses their sexual thoughts the blockage necessarily affects their body too: limbs may become paralyzed, speech impaired. Thus the psyche is simultaneously a bodily and mental formation.

Unfortunately, Freud compromises all these insights with his emphasis on the causal effects of anatomical sex difference, which makes it unclear how far the psyche has its own dynamics independent of biology, how unstable sexed identities are, and how far the body is something formed through and with the psyche. Moreover, Freud's emphasis on anatomy creates a litany of problems that initially impeded feminists from developing his insights. He takes it that girls love their mothers 'phallically'; that the penis is the only valued sexual organ; that both sexes

\footnotetext{
${ }^{2}$ Because sexual difference is neither social nor biological, (English-speaking) sexual difference feminists tend not to use the same clear distinctions masculine/male and feminine/female that sex/gender feminists do. Instead, sexed identity as (say) a woman is sometimes described as just that, at other times as feminine or female identity.
} 
inevitably see the female body as 'castrated' (this sight brings the castration threat home to boys); and that women's whole emotional lives revolve around 'penis-envy'.

Feminist hostility to Freud persisted until the mid-1970s when Juliet Mitchell’s 1974 book Psychoanalysis and Feminism prompted a sea-change. Mitchell's central point is that Freud gives us a largely accurate description of what it is to become a woman under patriarchy (Mitchell 1974: xiii). In a civilization that accords superior status to fathers (patriarchy means 'rule of the father') and so, too, to men and symbols of paternal and masculine status, girls cannot avoid learning that, being female, they are of lesser status. Coming to measure female bodies by masculine standards, girls judge themselves defective and second-rate. Freud's mistake was to portray this process as the effect of anatomy and not culture.

Mitchell was informed by the revision of psychoanalysis developed by Jacques Lacan in France, particularly in his 'structuralist' phase of the 1950s and 1960s, crystallized in his 1966 Écrits (Lacan 2002). Although Lacan claimed to return to Freud, in fact he shifted the focus of psychoanalysis away from biology to language and culture, rethinking the castration and Oedipus complexes as reflecting the structure of language, not the facts of anatomy. Because Lacan thus moved away from Freud's view that women's inferiority is biologically determined, Mitchell and many other feminist theorists found Lacanian psychoanalysis useful.

For Freud, the castration threat was issued by the father or in his name. From this Lacan takes the idea that there is a paternal function, which is to say 'no' (he calls this the Non/Nom-du-Père), to prohibit the bodily union with the mother for which the child wishes (Lacan 2002: 208). Lacan equates this paternal 'no' with the incest taboo, the universal taboo that separates culture from nature. This taboo is common to all cultures and societies - and to all the systems of kin relations by which 
we demarcate ourselves from animals. In all such systems, kin positions are defined in relation to one another: only father may have sex with mother, thus the position of the father is always to say 'no'. For the child to grasp these meanings father, mother, child, no, is to enter language and its system of distinctions (Lacan 2002: 66).

These points depend on Lacan's structuralist view that language is neither a neutral tool of communication nor a simple vehicle for expressing pre-existing ideas that in turn mirror the external world. Rather, for Lacan, language shapes how we see the world, constituting a horizon of meaning by which all experience is mediated. Each language does this by virtue of being a complete system of differences: each term gains meaning from its differences from and relations to all the others. For example, in French mouton can mean sheep or mutton, conveying a different view of sheep - as always potential meat - to English, which distinguishes the two terms. Kinship terms, then, do not simply describe pre-existing positions but establish kin positions with particular valences. Kinship is not separate from but entwined with the whole system of linguistic meanings which, in turn, organizes all our experience. In sum: fundamental to acquiring language is learning the meanings of the basic kinship positions that define each individual's place in the world; this requires learning that only father may desire mother, thus grasping the ban on union with the mother. Thus the father - as a symbolic figure - represents civilization and culture and is 'the original representative of the Law's authority' (Lacan 2002: 299). This 'father' is not the empirical, actually existing father (if indeed the child has one), who need not issue any threats. What matters is that the father have symbolic status as the one who alone may 'have' the mother, and that individuals and culture at large relay this to the child - perhaps by having 'church fathers', paternal heads of state, celebrating a culture's warriors and revolutionaries. Any civilization needs some 
arrangements to perform this paternal function of lifting the child out of his initial attachment to the mother into public, social life.

Lacan recasts the Oedipus complex as the wish to occupy the symbolic father's position and have its central emblem, the phallus, not the anatomical penis. Lacan says many things about the phallus: it is the badge of paternal status, of the father's sexual desire for the mother, and of the complete union with the mother that only the father may enjoy. The castration complex, in turn, centers on the child's realization that he or she may not occupy the father's position, or lacks the phallus. Even the little boy undergoes this kind of castration. Henceforward he wishes to acquire paternal status (likely by rebelling against the society’s symbolic fathers - for the rebel claims authority against those in power; law and rebellion are interdependent). Yet no boy or man can ever attain paternal status psychically, for Lacan, for each man takes the father's 'no' into his psyche, where it becomes the core of his superego (the prohibitive, punitive moral agency in the psyche) and of the idealized internal father-figure against which each man judges himself inadequate. Because the phallus symbolizes both what we want to have and that which we lack just in wanting it, it also comes to stand for our lack of paternal status, our castration.

For Lacan girls, too, must enter civilization by way of the Name-of-the-Father. To exit the pre-verbal bond with the mother and enter broader social life, mediated by language, the girl as much as the boy must relate to the paternal ideal - not to a maternal one, for the mother stands for the pre-social realm that must be exited. In the nature of language, then, the only possible subject-position is one arranged under the 'paternal function': to become a speaking subject is to become a masculine subject. Structural linguistic constraints forbid women from existing as specifically feminine subjects, from speaking or desiring in any specifically female way. 
In what sense, then, do women become feminine? The answer is that they can never fully assume the position of (masculine) subject but on entering language become, effectively, split between their subjectivity and their femininity, which locates them as objects, not subjects, of desire and speech. This happens through the role of the phallus. While the phallus is not the penis, it still constrains girls to undergo castration on different terms to boys. By (however mistakenly) equating his penis with the phallus, the boy can position himself as lacking and desiring to attain the paternal position of having the mother or woman. Unable to likewise represent and experience her desire as phallic because she has no penis, the girl is constrained to assume a different relation to the paternal phallus. The only available option here is to (strive to be) the object of the father's or man's phallic desire. Insofar as the girl takes up this feminine position, she is object; insofar as she speaks, desires, etc., she is (effectively) masculine.

We may take from Lacan's work several overarching points. First, that sexual difference is both the symbolic difference between the positions father/man and mother/woman - which map onto the difference subject/object - and the psychical difference between subjects who assume these distinct positions. Language and psyche thus interlock; Lacan calls their total complex the 'symbolic order'. Sexual difference as it exists within this order is reducible neither to biological sex difference nor to social gender as social norms define it; rather, sexual difference is symbolic, that is, at once linguistic and psychical. Being linguistic, sexual difference arises in the break with pre-verbal nature through which we which enter civilization, so that our sexed identities are always insecure, incomplete, defined in different ways by our confrontation with lack and insufficiency rather than giving us any sense of sexed wholeness. 
Various feminist theorists in the 1970s and 1980s took forward Lacan’s emphasis that sexed identity is never complete, campaigning relentlessly against any notion of being a 'whole woman’ or ‘whole man' (see, especially, Adams and Cowie 1992). Yet for Lacan the symbolic order that regulates these incomplete identities is fixed for all time. The paternal 'no' must be law and the phallus the 'master signifier' in every society - any society that does not meet these constraints faces collapse. Lacan holds out no prospect of changing the exclusion of women as women from civilization, then: despite their incompleteness, our sexed identities are here to stay.

This problem stems from the concept of sexual difference as it has taken shape in Lacan. Positively, the concept highlights that our psyches and systems of meaning have their own organization, not reducible to that of society; rather, there are constraints on the psyche and on possible systems of meaning which all societies must accommodate. However, negatively, Lacan puts at the centre of these constraints the necessity of separating from the mother with reference to a paternal ideal. Given this constraint, any language and any system of psychical organization must leave women split between speaking subjectivity and objectified femininity, something that no change to social gender norms can overcome.

We might escape these problems by abandoning psychoanalysis or reworking it without the concept of sexual difference. ${ }^{3}$ But then we lose the insights that the

\footnotetext{
${ }^{3}$ Nancy Chodorow (1978) reframes sexual difference as the gender difference between girls and boys that results from social conditions in which only women mother while men are breadwinners. Because mothers unconsciously identify more with their daughters while pushing their sons away, girls develop personalities that are empathetic, caring, with a blurred sense of self, while boys become abstract, detached, independent. Thus the gender division of labor becomes reproduced in the
} 
concept distils: that the psyche has its own dynamics, powered by the complex processes by which we acquire sexed identities that are always fluctuating and unstable; and that these psychical dynamics are bound up with deep-lying structures of meaning that overarch particular linguistic and social variations. We are left with an 'impasse' between feminism and psychoanalysis (Brennan 1991), between the insights of psychoanalysis and the feminist project of effecting social change. It was chiefly Luce Irigaray whose work broke this deadlock.

\section{Luce Irigaray’s Philosophy of Sexual Difference}

The foremost philosopher of sexual difference, Irigaray’s work has massively influenced feminist thought - particularly her earlier work of the 1970s, translated and imported into the English-speaking world from the 1980s onwards. ${ }^{4}$ Initially Irigaray belonged to Lacan's psychoanalytic school, the Parisian École Freudienne, but she was expelled because, throughout her earlier writings, she (indirectly) criticizes Lacan for falsely raising patriarchy into the universal condition of human civilization.

Even so, Irigaray finds in Lacan the basis of a radical critique of Western civilization for its exclusion of any possibility of women speaking, thinking or acting as women. The symbol of subjectivity, the phallus, is modeled on a male body part; no female body part provides an equivalent symbol inspiring women to speak and

personalities of each generation. Through shared parenting, Chodorow argues, the cycle could be broken. However, Parveen Adams (1981), a Lacanian, rightly criticizes Chodorow for reducing psychical to social processes.

${ }^{4}$ Irigaray is reluctant to embrace the label 'feminism', but has been received as contributing to it nonetheless. 
desire specifically as women. This is indicative of how woman has been cast as object, not subject, with the position of speaking, thinking subject exclusively male: 'any theory of the "subject” will have always been appropriated as "masculine”, (Irigaray 1985a: 133). More broadly, the feminine has been construed only as the negative, inferior version, or opposite of the masculine: always defined in relation to, against, and beneath the masculine, paradigmatically as object in contrast to the masculine subject. 'The "female” is always described as deficiency, atrophy, lack of the sex that has a monopoly on value: the male sex’ (Irigaray 1985b: 69).

These hierarchical meanings of male and female, masculine and feminine, are at the core of the Western symbolic order. They organize a whole set of binary oppositions that make up this order, i.e. the underlying structure of meaning that constitutes the backbone of Western culture - contrasts of mind/body, culture/nature, reason/emotion, reality/appearance, truth/deception, good/evil, active/passive, order/chaos. All are shot through with sexed meaning: women are closer to nature, are all liars, at the mercy of their emotions, etc. ${ }^{5}$ Being female has not been the source of

\footnotetext{
${ }^{5}$ As Hélène Cixous puts it:
}

Where is she?

Activity/Passivity

Sun/Moon

Culture/Nature

Day/Night

Father/Mother

Head/Heart 
an independent subjective identity but merely the inverse of being male, which has been taken to be a positive identity. Women can escape their second-rate condition only by positioning themselves as non-feminine: perhaps as sex-neutral reasoners or speakers (yet who in fact are covertly taking up a masculine position from which their femininity always threatens to drag them down).

Irigaray concludes that no real sexual difference has ever existed at the symbolic level, in the sense that it is only as a man that one has been able to be a thinking, speaking, acting subject. Rather than genuine difference, there has only ever been hierarchy and binary opposition between 1 and 0 , where 1 is male, 0 the female construed as mere lack. Irigaray nevertheless refers to this traditional refusal of genuine difference as sexual difference, under the hierarchical, oppositional interpretation it has had up to now.

Contrary to Lacan, Irigaray argues that this symbolic order that has ruled the West is only one of many possible symbolic orders. Our particular order originated in classical Greece. She refers here to the tragic trilogy the Oresteia, by Aeschylus (Irigaray 1991). The hero, Orestes, kills his mother Clytemnestra in revenge for her murdering his father Agamemnon. The Athenian court eventually acquits Orestes, making the 'murder of the mother' a founding principle of the classical social order. For Irigaray this exemplifies how, at this point in history, a particular 'imaginary'

Intelligible/Palpable ...

$\underline{\text { Man }}$

Woman

Always the same metaphor: ... wherever discourse is organized. (Cixous 1986: 63) 
became law (1988: 159) - that is, was articulated into the symbolic order that has prevailed since.

By an 'imaginary’, Irigaray means a structured, interrelated set of fantasies, where a fantasy consists of ideas about what we wish for conjoined with bodily energies that charge and eroticize them. The fantasies informing the Western symbolic are, like all our most fundamental fantasies, very deep-seated and not under our conscious control; they concern the figures of the mother and father, and arise, Irigaray holds, from the peculiar difficulties that little boys face after their birth (Irigaray 1995: 107-8). All small children struggle to separate themselves from their mothers emotionally and establish a sense that they differ from their mothers in mind and body. But unlike girls, boys are born of women who differ from them in sex. The separation from the mother that boys need to make is therefore sharper than for girls. So boys become motivated to sever all ties with their mothers at an emotional and fantasy level, and to devalue the mother and all that she stands for: the body, dependency, close relationships, passions. Effectively, boys wish to deny that they lose anything by separating from the mother by casting her entire realm as valueless and as a realm to which boys never truly belonged anyway.

To accomplish this, boys raise the father-figure into the bearer of all the values that they set against the mother and the world of dependent infancy that she stands for: disembodiment; independence; separateness from others; reason as opposed to emotion. The boy aspires to embody these values, projected onto an idealized paternal position. When these fantasies are expressed as a symbolic order, culture becomes structured by binary oppositions set out along sexed lines, as illustrated by documents such as the Oresteia. Hence the patriarchal symbolic order described by Lacan - but Irigaray has now traced its roots in the little boy’s early relation with his mother. 
By seeing the symbolic order as an expression of (male) fantasies, Irigaray reemphasizes the bodily roots of meaning, which had become somewhat lost in Lacan's work and its initial feminist reception. Ideas and bodily energies converge in fantasies, so that we have a stubborn corporeal attachment to them. The fantasies that underlie the Western symbolic order concern the mother and father as bodily figures, for this is how we experience them in infancy. The symbolic man/woman opposition that expresses these fantasies thus attributes hierarchical meanings to male and female bodies - as when Plato took the female womb and genitals as his model for the cave of sensory ignorance and illusion in which he believes we are all trapped.

But how does Irigaray think that the symbolic order can be changed, if it expresses male fantasies to which boys are drawn because they are born male of female mothers? Irigaray's view that symbolic change is possible rests on her belief that the relation between symbolic and imaginary is reciprocal. As Margaret Whitford puts it in her exposition of Irigaray, the imaginary is a 'magma' (Whitford 1991: 57) that only becomes molded into definite shape when expressed as a symbolic order. Prior to this kind of expression, fantasies are not fully definite and determinate; they are fleeting, mobile. Boys’ infant situation inclines them towards certain fantasies, then, but these only settle into a fixed pattern through being expressed symbolically. So, we could channel our fantasies into different configurations if we changed our symbolic order.

Indeed, because the symbolic order structures our fantasies, which draw on drive-energies, we come to incorporate this order into our bodies. Our energies and desires become fixed into definite patterns affecting how we move, feel, act. For a woman to apprehend that being feminine is something defective, an inferior version of the masculine, is to come to live and feel this status in her body, perhaps as a 
visceral dislike or shame of her own body manifested, say, in eating disorders or shamefully hiding parts of her body. Irigaray understands this process of incorporation using the term 'morphology' (or 'imaginary morphology'), by which she refers both to collective cultural meanings surrounding our sexed bodies and to the resulting ways that we, as individuals, come to experience, feel and lived our bodies. A body's morphology - from the Greek terms morphe, form, and logos, meaning - is its meaning and energetic patterns.

But what motivation do we have to change the symbolic order, if it structures our fantasies and bodies so that we are emotionally attached to patriarchy? Fortunately the imaginary-symbolic fit is never total and seamless. Our psyches always contain imaginary elements that go beyond the expressive resources of the symbolic. Men have psychical remnants of their early attachments to their mothers; and women's fantasy lives, of their many kinds, find only partial outlet in the current symbolic. For example, as the little girl learns that being female is a second-class status she turns against her mother. Thus the girl's feelings of aggression and hostility towards her mother gain symbolic expression, but not her earlier attachment to and love for her mother - or her love for her own body qua female. Thus, much of women's potential desires, fantasies, self-love, bodily feelings has no morphology at present, because our symbolic order gives it no outlet.

To change the symbolic order, we need to activate and express these alternative elements in our psyches and bodies. To this end Irigaray (1985b) puts forward imagery of women's 'two lips' - two sets of lips, oral and genital - touching one another, constantly communicating. A counter-symbol to the phallus, the 'two lips’ raises women’s anatomy into a sign of how women can speak specifically as women. The image is also intended to provide an expressive vehicle through which 
female self-love, self-esteem, and desire can come into culture - through which the female body can attain its own morphology.

This shows us what particular kind of symbolic change Irigaray favors. In her view, we need to create a culture of sexual difference - not a gender-neutral culture, but one that recognizes and celebrates genuine sexual difference for the first time. Being female-bodied must be completely re-imagined as the basis of a positive identity in its own right. Then, being a woman would mean being a particular kind of speaking, thinking, acting subject, whose speech embodies a distinctively feminine set of fantasies and bodily processes. Reciprocally, male identity needs to be re-imagined as a specific identity: one of two, not the only one.

We see why Irigaray declares that 'Women’s exploitation is based upon sexual difference; its solution will only come about through sexual difference’ (1993: 12). The problem is sexual difference as the West has understood it - as a lack of genuine difference, a binary opposition. The solution is genuine sexual difference, to come about through the creation of a symbolic order that recognizes it at last.

In sum, for Irigaray, the West has basic symbolic meanings concerning male and female, father and mother, which organize a whole series of binary oppositions reflected in all the more manifest representational schemes found in this culture. These basic meanings define sexual difference in the first of the complex of senses that this term has for Irigaray, namely the symbolic difference (hierarchy) between male and female. In this first sense, sexual difference is the difference between men and women, male and female, as it is imagined, fantasized and symbolized in Western culture. Second, sexual difference is also the psychical difference between actual men and women - their different fantasies, desires, inner lives - a difference that results from their assuming the positions male or female as the symbolic order defines them. 
Since the psyche is in part bodily, this difference includes the embodied difference between being male and being female as we experience it at a felt, bodily level.

Sexual difference as Irigaray understands it differs from social gender in several ways. As a symbolic and imaginary contrast, sexual difference expresses deep-seated fantasies that are not straightforwardly social in origin, if by 'society' we mean a set of collective arrangements into which each individual comes and by which he or she is shaped. Rather, our shared fantasies about sexual difference originate in the (male) subject in response to his earliest relationships with others, primarily his mother. These relationships are interpersonal, arising between subjects, and reflecting the inside of the subject as much as or more than the public life that frames interpersonal relationships. So, insofar as the symbolic order has roots in the psychic life of the subject, it is not directly social, for as Irigaray says, 'the human subject, woman or man, is not a mere social effect’ (Irigaray and Lotringer 2000: 11). Furthermore, for Irigaray, men and women assume different subject-positions by taking on these symbolic meanings, a process that establishes our basic identities as men and women (boys and girls). Only having taken on the rudiments of these identities do we then come to respond to and take on particular - socially and historically changing - gender norms. Moreover, our sexed identities are psychical and bodily, unlike gender roles which are taken on by the mind rather than the body.

Even so, shifting our attention from gender norms to sexual difference may seem unhelpful. The shift is to a highly abstract level of analysis, away from practical problems such as unequal pay or domestic violence. Indeed, the theoretical abstraction of Irigaray's earlier work has been criticized. Perhaps in response, she made her writing of the later 1980s more practical, sketching out a politics of sexual difference. Let us turn to this. 


\section{The Politics of Sexual Difference}

The politics of sexual difference is defined, above all, in opposition to a politics of pursuing equality for women. The aim of equality politics - associated with the liberal feminism of groups such as the National Organization for Women - is to enable women to participate equally in the public worlds of paid work and politics. This requires, first, securing women's formal legal equality with men (rights to equal pay, against sexual discrimination, etc.) and then real, substantial equality. The latter requires dismantling the panoply of informal barriers that hold women back: such as the unequal distribution of housework and childcare, which remain largely women's work; implicit biases against women held by appointments and promotions panels; long hours cultures and old boys’ networks in politics and business.

Irigaray's rhetorical question to the proponents of this politics is: Equal to whom? The equality sought is with men: the aim of equality politics is to bring women into spheres that have been historically defined as the province of men, a definition that has shaped their structure and significance. Paid work, politics, etc., do not lose these entrenched masculine connotations just because women enter into them. Instead, women entering these fields become forced to comply with their preexisting masculine meanings and to model themselves on men - as when female politicians such as Margaret Thatcher or Sarah Palin adopt the same belligerent rhetoric and policies as (many) male politicians. From Irigaray’s perspective, far from challenging patriarchy, equality politics reinforces it by perpetuating the age-old system that recognizes only one ideal, the masculine, to which men and women alike 
must aspire. Thus Irigaray (and other sexual difference feminists) complain that pursuing equality means pursuing sameness - making women the same as men.

This criticism may seem unfair to equality politics. Arguably women cannot achieve real equality unless the institutions that they enter change, perhaps to recognize and incorporate women's difference. Treating men and women equally may require that they be treated differently in some respects. For example, perhaps women need paid maternity leave, the option of flexible work schedules, state-subsidized childcare at every workplace, and facilities at work for caring for babies, before they can hope to participate equally in paid work, given their 'difference' - in this case the special responsibility for childcare that society (and maybe to an extent biology) assigns to women. However, such provisions, intended to further women’s inclusion in the public sphere, may reinforce the very 'difference' that hinders women from achieving full inclusion.

Either way, the politics of sexual difference is not a politics of difference in this last sense. Sexual difference feminists do not aim to reshape social institutions so that they value, celebrate, recognize or support women's difference as it already exists, because for these feminists this is not a genuine difference. Women's traditional role as mothers, for instance, is just one way in which women have been defined in relation to men, as good women if they love and care for men (e.g. the Virgin Mary caring for baby Jesus), bad women if they harm men or male interests. Motherhood has been seen not as a possible part of female subjectivity but as a mere 'function', that of providing the caring background in which (infant male) subjectivity takes shape. To accommodate this or other traditional differences of women would be just another way of perpetuating patriarchy. 
Still, in defense again of equality politics, we might wonder whether achieving real equality for women requires a more wholesale transformation of the institutions of paid work and politics - not so as to accommodate differences that have been heaped exclusively onto women but so as to treat all individuals differently than under traditional, gender-divided practice. Workplaces could be restructured to assume that all paid workers also care for family members and to value the same. Sexual difference feminists would agree that radical transformation is needed - but of what kind? For them, the goal is not to treat all individuals alike but to create social structures that recognize genuine sexual difference and, by doing so, create it for the first time. Whereas equality feminists tend ultimately to valorize a gender-neutral future, sexual difference feminists valorize a future symbolic order of two sexes. Their aim is to invent new social practices to make that order a reality.

Irigaray’s proposals in this regard are mainly for new laws. She says that we must go about 'Redefining rights appropriate to the two sexes to replace abstract rights appropriate to non-existent neutral individuals, and enshrining these rights in the law ... civil law must be changed to give both sexes their own identities as citizens’ (Irigaray 1994, xv-Xvi). In particular, she proposes, women should have (1) the right to economic equality and equal representation on all civil and religious bodies, (2) the right to defend their own cultures and traditions, (3) the right to 'human dignity’, especially through positive representations of women in public places, and (4) rights to choose motherhood freely and to enjoy 'physical and moral integrity' (1993: 86-89). These legal rights are intended to begin the work of creating a positive identity for women as women. Thus, Irigaray envisages the proposed equal representation of women on all civil and religious bodies in terms of women's representation there as women, who could as such contribute to these bodies from 
distinctly female perspectives (starting to create those perspectives just by articulating them). Irigaray is not opposed to women entering the professions or agencies of government, indeed she advocates this - but she seeks ways that they can do so as women, without having to relinquish their femininity.

Further applications of the politics of sexual difference can be found in the history of Italian feminism. While Italy, like other countries, has always contained various feminist currents, from the late 1970s and 1980s onwards several Italian groups began to raise sexual difference into one such political current. Importing psychoanalytic and philosophical ideas along with US radical feminism and Irigaray, these Italians (of whom Adriana Cavarero is best known to English speakers - see, e.g., Cavarero 1995) moved away from directly socio-economic issues to pursue a radical transformation of the fundamental structures of subjectivity and meaning. The entire social world was to be reshaped to accommodate two different kinds of subject. This project manifested itself concretely in a range of ways.

For example, in 1986 L'Unità called for women to demonstrate in response to the disastrous nuclear 'accident' at Chernobyl, which was, L'Unità declared, the predictable result of a scientific practice detached from material life and abstracted from our bodies, bodies that are necessarily sexed (Bono and Kemp 1991: 317). Since our thought, therefore, is in fact sexed - the product of the thinking activity of embodied, sexed beings - such science only masquerades as disembodied while really expressing the destructive priorities of the male sex, contrary to 'a way of thinking which cares about life ... [that] has always been with women’ (318). Such statements fed into heated debate about whether the demonstrators demonized men and falsely exalted women. Lia Melandri objected that women are complicit with modern science and its outcomes (328-9). Members of the Milan Women's Bookstore Collective - 
one of the main Italian groups articulating the politics of sexual difference - replied that, even so, women are still complying with institutions made by and for men. Plus, the Collective added, there are always parts of women's desire that go beyond and can turn women against the existing order (330).

The Collective developed various strategies for bringing about a culture of sexual difference. One was the controversial practice of affidamento - 'entrustment' or 'custody’ (see Milan Women’s Bookstore Collective 1990; Zerilli 2004). The idea is that women can only fully realize their talents and abilities if they accept and use their inequalities (of age, status, etc.), rather than stifling women's potentials in the name of a fictitious equality. A younger or junior woman should place herself under the custody or tutelage of a woman her superior in age or professional standing, from whom she learns how to realize her potential as a woman, with reference to a female role model. At a broader cultural level, too, women are to recognize female authorities - 'symbolic mothers'. This position led to the establishment of women's bookstores and libraries in various cities, publishing houses devoted to women's writing, and the Virginia Woolf Cultural Centre in Rome. These institutions embody the ideal of a symbolic mother - a female bearer of authority and knowledge - whose position women can aspire to occupy as women.

Having said all this about the specificity of feminism of sexual difference, its partisans may ultimately remain committed to women's equality in a fundamental moral sense. After all, they want women to be treated, at a moral level, as subjects fully equal with men - but, they add, this requires women to have a sexuate identity in their own right, so that women cease to count only as second-class men. Even so, sexual difference feminists might reply that their goal is not equality because the generally accepted meaning of gender equality is treating all individuals alike. At the 
least, sexual difference feminists are transforming the meaning of equality; if the language of equality masks this transformation, then it is best avoided. Anyway, what is clear is that, abstract and theoretical as it is, the concept of sexual difference has sparked a range of political interventions and strategies that have fed into feminism's diversity and vitality.

\section{Sexed Bodies: Beyond the Sex/Gender Distinction}

The concept of sexual difference has sometimes been defended on the grounds that it advances beyond perceived problems with the sex/gender distinction. So argues Moira Gatens, in particular, in her 'Critique of the Sex/Gender Distinction’ (Gatens [1983] 1996: ch. 1), a paper which has been very influential and remains important. For Gatens, the sex/gender distinction has several problems. It sharply distinguishes the biological body from the mind, taking it that it is through our minds that we take on gender norms (1996: 9). The distinction suggests that our gender is taken into our personalities without this process having any intrinsic connection with our bodies, which sit inertly by whilst gender acquisition takes place.

Thus, the distinction is a legacy of Descartes’ mind/body dualism. Feminists, though, should be wary of mind/body dualism, which is continuous with the long-standing symbolic hierarchy that aligns body with woman and mind with man. In addition, Gatens maintains, the sex/gender distinction comes close to suggesting that the mind is a blank slate at birth onto which 'social lessons' concerning gender are written (4).

Gatens's proposed alternative, which she couches in terms of sexual difference, has affinities with Irigaray’s position. For Gatens, gender norms are actually bound up with value-laden interpretations of the meanings of male and 
female bodies which are held at a social, imaginary level (1996: 9). For example, the gender norm that women should not be aggressive reflects our social imaginary that pictures the female body as nurturing, peaceful and maternal. It is because the female body is so imagined that a corresponding set of gender norms arises (13). Thus, Gatens says, it is not the case that our social institutions simply value those traits that are deemed normal (or normative) for masculinity, such as scientific and reasoning skills. In that case those traits would equally be valued in women who succeed at science or reasoning. In fact, Gatens points out (9), society values the masculine male - the traits deemed normal for masculinity are only valued when men display them. If women - those with female bodies - do display those traits, excelling at science or reasoning for example, then their doing so is not valued but condemned for making them un-femininine (cold, unattractive, etc.).

Gatens further argues that, as individuals, we take on gender norms and imaginary meanings concerning the significance of sexed bodies at a bodily as much as a mental level. Indeed, we should not regard the mind and body as separate entities. We have already seen that Freud and Irigaray view the psyche as an organization of ideas and bodily energies both. Gatens adds insights into embodiment developed within the phenomenological tradition. Central for Gatens is the approach of Maurice Merleau-Ponty in The Phenomenology of Perception (Merleau-Ponty [1945] 2002). For Merleau-Ponty, I both have my body - as an object that I can perceive as if from without, as a third party can - and am my body - the one perceiving my body is that same body, as a living, sentient being imbued with vital awareness of itself.

On this basis Gatens suggests that it is as a body - the body that I am - that I apprehend, make sense of and internalize gender norms and imaginary meanings (1996: 11). I take these collective meanings into myself-as-body, where they become 
the meaning that my body has for me at an ongoing everyday level. Because the two sides of my embodiment (having and being my body) co-exist inseparably, these meanings come to saturate my body in its objective, perceptible aspect: they seep into my body’s ingrained habits, skills and patterns of movement, its gestures and properties. Thus women learn, for instance, to move differently to men - perhaps in a more restrained and modest way.

Gatens couches this position in terms of sexual difference in part because of its political implications. She opposes the politics of 'degendering' that, she believes, flows from the sex/gender distinction (1996: 5). According to that politics, we should dismantle and eradicate gender norms so that all individuals are treated alike, their sex being seen to have no rightful bearing on how people are treated: social life should, as far as possible, be abstracted from our bodies with their sex differences. Gatens objects, first, that this politics of neutralizing the body reflects our culture's longrunning male/female hierarchy, because this politics values what is symbolically male - mind, culture, society - over what is symbolically female - bodies. Second, she objects, this politics neglects the fact that we are our bodies, which as such are not merely biological objects (as the sex/gender distinction assumes) but are also the living individuals that we are. As such, no society can realistically hope to divest our bodies of significance (1994: 9).

We therefore need a different politics, one that starts by recognizing the inescapable significance of our sexed bodies but that strives to change the meanings attached to them, to render these meanings non-hierarchical. This politics championed by Gatens has clear links with the politics of sexual difference as articulated by Irigaray and others. Gatens, however, does not endorse the goal of changing the symbolic order to recognize two genuinely different sexes. For Gatens, our goal is 
more to change the meanings of male and female bodies so that they cease to be pitted in sharp opposition to one another and are re-imagined as overlapping along a spectrum (1996: 52).

It has been objected that Gatens is unfair to the sex/gender distinction. For Val Plumwood (1989), the sex/gender distinction does not inherently involve mind/body dualism as Gatens claims. Rather, Plumwood contends, 'gender' has always referred to the different norms and meanings expected of and attributed to females and males, who take on these norms at an embodied level, as specifying how they should be as female- or male-bodied individuals. For Plumwood, the sex/gender distinction already essentially accommodates all that Gatens says.

Another alternative, adopted by Judith Butler in her earlier work (e.g. Butler 1990), is to redeploy a sharp sex/gender distinction but in a newly radical way. Ordinarily, Butler maintains, it is assumed that an individual must have the gender that 'fits' their sex: females must be feminine, males masculine. Effectively, gender is expected to express sex. For Butler, the sex/gender distinction allows us to question this paradigm (the 'heterosexual matrix'), a harmful paradigm that marginalizes or makes 'unintelligible' all those who, in various ways, are transgressively gendered or sexed - including the intersexed, ${ }^{6}$ transsexuals, those whose gender does not 'fit' their sex, and those whose sexuality does not 'fit' their sex or gender. For Butler, the sex/gender distinction opens up a positive alternative: it entails that any gender can go along with any sex - a woman can be masculine, a man feminine; a woman can desire women, a man men; gender need not be polarized as when it is expected to 'follow'

\footnotetext{
${ }^{6}$ Until now I have spoken as if, biologically, everyone were either male or female, but a minority of people are born intersexed. Whether sexual difference theory can adequately accommodate this or any other variation on sexual duality is debated.
} 
sex, and a range of gender expressions can proliferate. From Butler’s perspective there is more radical potential in the sex/gender distinction than Gatens allows indeed, the distinction enables a politics of gender subversion that is ultimately more liberating than the politics of sexual difference.

\section{Further Directions}

Ideas of sexual difference have had a wide-ranging influence on contemporary feminist theory, and not only on those who explicitly embrace sexual difference feminism. The irreducibility of psyche to society; the embodied nature of the psyche and the inescapable significance of our sexed bodies; the symbolic disparity between men and women; language as a horizon of meaning rather than a neutral tool for communication - all these ideas are widely, although not universally, accepted.

Yet there have been major criticisms of the concept of sexual difference. Butler suggests that the construction of sexual difference as a hierarchy, while problematic in itself, may also mask a still-deeper exclusion of sexual minorities who defy or subvert the sexed binary. Another problem is that sexual difference feminists tend to regard sexual difference, not class or race, as the fundamental social-symbolic problem - Irigaray is explicit that 'the problem of race' is 'secondary' (1996: 47). To prioritize one form of oppression in this way unhelpfully pits the oppressed against one another and, plausibly, is misguided: gender oppression is not obviously more fundamental to the modern capitalist order than class or race.

More constructively, sexual difference feminism has enabled a host of new currents in feminist thinking to emerge, in part through the ongoing process of Anglophone theorists assimilating ideas about sexual difference. Amongst these 
currents are new directions in Irigaray's later work. She asks how to cultivate relations between women and men as subjects of irreducibly distinct kinds, and her whole view of sexual difference shifts. She now maintains that, naturally, there are two different sexes, and that our culture must be changed to express both their natures (Irigaray 1996). This shift has contributed to extensive debate, still ongoing, about how to interpret Irigaray’s ideas and take them forward (see, e.g., Deutscher 2002, Stone 2006).

Beyond Irigaray, sexual difference feminism has helped to make possible the emergence of 'material feminism’ (see Alaimo and Hekman 2008), which takes further the rejection of the sex/gender distinction. Rather than turning away from the biological body towards social gender for fear of falling into biological determinism, 'material feminists' rethink materiality as an active, dynamic, creative force - an agency of change, supporting our efforts to change society for the better. Sexual difference theorists have attended to the body but in its psychical and cultural significance, as experienced. Effectively, these theorists bring the body into the fold of culture. For material feminists, though, this neglects the biological aspects of the body and how these aspects affect what psychical and cultural significance the body takes on. Material feminists thus aim to address the body’s specifically biological aspects, as they are theorized by the sciences - be they Darwinian evolutionary theory, neurobiology or quantum physics (see, respectively, Grosz 2004, Wilson 2004, Barad 2007).

Likewise building on sexual difference theory's attention to the lived body, a growing number of feminists are engaging with phenomenology to think about embodiment. This includes inquiry into natality - our existential condition as beings who are born of women; into women's lived experiences of pregnancy, birth-giving 
and mothering; and renewed attention to our experience as corporeal, fleshly beings (see, e.g., Schott 2010).

A final current deserving mention is feminist psychoanalysis. If the psyche has its own dynamics, these are not necessarily only those of the Oedipus and castration complexes - real as those complexes may be under patriarchy. There may be further fantasies, complexes, processes that Freud and Lacan missed. Amber Jacobs (2007) identifies a law of the mother - 'you shall not be in the place of the generative mother yet (girl) or ever (boy)' - which the West has repressed, yet which has covertly retained great power. Freud himself belatedly noticed the lifelong importance of women's earliest, 'pre-Oedipal' ties to their mothers (Freud 1973). From this startingpoint I have explored a psychical pattern for mothers to relive with their young children their earliest relations with their own mothers (Stone 2011).

As this overview of emerging directions illustrates, ideas about sexual difference continue to feed into the diversity and vitality of contemporary feminist thought. These ideas are unlikely to lose their influence, given that they address issues fundamental to feminist thought - the significance of the body, how far social change can change the psyche, how being female can or could perhaps become a positive identity. So we can expect that sexual difference will be reconceived in unexpected new directions in the future.

\section{References}

Adams, Parveen. 1983. 'Mothering'. m/f 8: 40-52. 
Adams, Parveen, and Elizabeth Cowie. 1992. The Woman in Question. Cambridge, Mass: MIT Press.

Alaimo, Stacy and Susan Hekman, eds. 2008. Material Feminisms, Bloomington, IN: Indiana University Press.

Barad, Karen. 2007. Meeting the Universe Halfway: Quantum Physics and the Entanglement of Matter and Meaning, Durham, NC: Duke University Press.

Bono, Paola and Sandra Kemp, eds. 1991. Italian Feminist Thought: A Reader. Oxford: Blackwell.

Brennan, Teresa. 1991. ‘An Impasse in Psychoanalysis and Feminism’. In A Reader in Feminist Knowledge, ed. Sneja Gunew, 114-138. London: Routledge.

Butler, Judith. 1990. Gender Trouble. New York: Routledge.

Cavarero, Adriana. 1995. In Spite of Plato: A Feminist Rewriting of Ancient

Philosophy. Trans. Serena Anderlini-d’Onofrio and Áine O’Healy. Cambridge, UK: Polity Press.

Chodorow, Nancy. 1978. The Reproduction of Mothering: Psychoanalysis and the Sociology of Gender. Berkeley, CA: University of California Press.

Cixous, Hélène and Catherine Clément. 1986. The Newly Born Woman. Trans. Betsy Wing. Manchester: Manchester University Press.

Deutscher, Penelope. 2002. A Politics of Impossible Difference: The Later Work of Luce Irigaray. Ithaca, NY: Cornell University Press.

Freud, Sigmund. 1973. Femininity. In New Introductory Lectures on Psychoanalysis, trans. James Strachey, 145-69. Harmondsworth: Penguin.

Freud, Sigmund. 1977a. Some Psychical Consequences of the Anatomical Distinction Between the Sexes. In On Sexuality, ed. Angela Richards, 323-43. Harmondsworth: Penguin. 
Freud, Sigmund. 1977b. Female Sexuality. In On Sexuality, edited by Angela Richards, 371-92. Harmondsworth: Penguin.

Gatens, Moira. 1996. Imaginary Bodies: Ethics, Power and Corporeality. London: Routledge.

Grosz, Elizabeth. 1990. Jacques Lacan: A Feminist Introduction. New York: Routledge.

Grosz, Elizabeth. 2004. The Nick of Time: Politics, Evolution and the Untimely, Durham, NC: Duke University Press.

Irigaray, Luce. 1985a. Speculum of the Other Woman. Trans. Gillian C. Gill. Ithaca, NY: Cornell University Press.

Irigaray, Luce. 1985b. This Sex Which Is Not One. Trans. Catherine Porter with Carolyn Burke. Ithaca, NY: Cornell University Press.

Irigaray, Luce. 1988. Interview with E. H. Baruch and J. L. Serrano. In Women Analyze Women, ed. Baruch and Serrano, 149-164. New York: New York University Press.

Irigaray, Luce. 1991. The Bodily Encounter with the Mother. In The Irigaray Reader, ed. Margaret Whitford. Oxford: Blackwell.

Irigaray, Luce. 1993. Je, Tu, Nous: Toward a Culture of Difference. Trans. Alison Martin. London: Routledge.

Irigaray, Luce. 1994. Thinking the Difference. Trans. Karin Montin. London: Athlone. Irigaray, Luce. 1995. 'Je - Luce Irigaray': A Meeting with Luce Irigaray. Interview with Elizabeth Hirsh and Gary A. Olson. Hypatia 10 (2): 93-144.

Irigaray, Luce. 1996. I Love to You: Sketch for a Possible Felicity in History. Trans. Alison Martin. London: Routledge. 
Irigaray, Luce, and Sylvère Lotringer. 2000. Why Different? A Culture of Two Subjects. Trans. Camille Collins. New York: Semiotext(e).

Jacobs, Amber. 2007. On Matricide: Myth, Psychoanalysis, and the Law of the Mother. New York: Columbia University Press.

Lacan, Jacques. 2002. Écrits: A Selection. Trans. Bruce Fink. New York: Norton. Merleau-Ponty, Maurice. 2002. The Phenomenology of Perception. Reprint edn. Trans. Colin Smith. London: Routledge.

Milan Women’s Bookstore Collective. 1990. Sexual Difference: A Theory of SocialSymbolic Practice. Trans. Patricia Cigogna and Teresa de Lauretis. Bloomington, IN: Indiana University Press.

Mitchell, Juliet. 1974. Psychoanalysis and Feminism. Harmondsworth: Penguin. Oakley, Ann. 1972. Sex, Gender and Society. London: Maurice Temple Smith. Plumwood, Val. 1989. Do We Need a Sex/Gender Distinction? Radical Philosophy 51: 2-11.

Schott, Robin May, ed. 2010. Birth, Death and Femininity: Philosophies of Embodiment. Bloomington, IN: Indiana University Press.

Stone, Alison. 2011. Feminism, Psychoanalysis and Maternal Subjectivity. London: Routledge.

Whitford, Margaret. 1991. Luce Irigaray: Philosophy in the Feminine. London: Routledge.

Wilson, Elizabeth. 2004. Psychosomatic: Feminism and the Neurological Body, Durham, NC: Duke University Press.

Zerilli, Linda. 2004. Refiguring Rights Through the Political Practice of Sexual Difference. differences 15 (2): 54-90. 